\title{
A molecular view of heterogeneous catalysis
}

\author{
Christensen, Claus H.; Nørskov, Jens Kehlet
}

Published in:

Journal of Chemical Physics

Link to article, DOI:

$10.1063 / 1.2839299$

Publication date:

2008

Document Version

Publisher's PDF, also known as Version of record

Link back to DTU Orbit

Citation (APA):

Christensen, C. H., \& Nørskov, J. K. (2008). A molecular view of heterogeneous catalysis. Journal of Chemical Physics, 128(18), 182503. https://doi.org/10.1063/1.2839299

\section{General rights}

Copyright and moral rights for the publications made accessible in the public portal are retained by the authors and/or other copyright owners and it is a condition of accessing publications that users recognise and abide by the legal requirements associated with these rights.

- Users may download and print one copy of any publication from the public portal for the purpose of private study or research.

- You may not further distribute the material or use it for any profit-making activity or commercial gain

- You may freely distribute the URL identifying the publication in the public portal

If you believe that this document breaches copyright please contact us providing details, and we will remove access to the work immediately and investigate your claim. 


\title{
A molecular view of heterogeneous catalysis
}

\author{
Claus Hviid Christensen ${ }^{1}$ and Jens K. Nørskov ${ }^{2, a)}$ \\ ${ }^{1}$ Center for Sustainable and Green Chemistry, Department of Chemistry, NanoDTU, Technical University \\ of Denmark, DK-2800 Lyngby, Denmark \\ ${ }^{2}$ Center for Atomic-scale Materials Design, Department of Physics, NanoDTU, Technical University \\ of Denmark, DK-2800 Lyngby, Denmark
}

(Received 12 October 2007; accepted 8 January 2008; published online 12 May 2008)

\begin{abstract}
The establishment of a molecular view of heterogeneous catalysis has been hampered for a number of reasons. There are, however, recent developments, which show that we are now on the way towards reaching a molecular-scale picture of the way solids work as catalysts. By a combination of new theoretical methods, detailed experiments on model systems, and synthesis and in situ characterization of nano-structured catalysts, we are witnessing the first examples of complete atomic-scale insight into the structure and mechanism of surface-catalyzed reactions. This insight has already proven its value by enabling a rational design of new catalysts. We illustrate this important development in heterogeneous catalysis by highlighting recent examples of catalyst systems for which it has been possible to achieve such a detailed understanding. In particular, we emphasize examples where this progress has made it possible to propose entirely new catalysts, which have then been proven experimentally to exhibit improved performance in terms of catalytic activity or selectivity. (C) 2008 American Institute of Physics. [DOI: 10.1063/1.2839299]
\end{abstract}

\section{INTRODUCTION}

A catalyst is a substance that can facilitate a chemical reaction and catalysis is the means by which both modern society and nature control chemical processes. Catalytic technology affects our everyday lives in many ways: it provides a range of products from fuels and fertilizers to plastics and pharmaceuticals. It is also used to clean emissions from cars, power plants, and industrial production. The technology is essential to our economy. It has been estimated that $20 \%$ $30 \%$ of production in the industrialized world is dependent on catalysis. ${ }^{1}$ We are facing enormous new challenges that call for an even larger focus on catalysis. The realization that the way we produce energy may jeopardize the Earth's climate points to accelerated investments in alternative energy production technologies, and catalysis is central to most scenarios being discussed.

Catalysts are often used solely because of their activity, that is, their ability to enhance the rate of a chemical reaction, often by many orders of magnitude. In other cases, catalysts are desirable because of their selectivity, i.e., their ability to specifically increase the rate of formation of one particular reaction product relative to that of other possible but unwanted by-products. Control of the absolute rate and the product distribution of chemical reactions is a major challenge of paramount importance; catalysis is at the heart of chemistry.

Traditionally, the field of catalysis is subdivided into the three areas of heterogeneous, homogeneous, and enzyme catalysis. Heterogeneous catalysts are present in a phase different from that of the reactants; usually, the catalyst is a solid surface. Homogeneous catalysts operate in the same phase as

${ }^{a)}$ Electronic mail: norskov@fysik.dtu.dk. the reactants. Enzyme catalysts are specialized proteins. For both homogeneous and enzyme catalysis, it has been possible to reach molecular-scale insight into the structure of the active site and the reaction mechanism for a multitude of catalysts and reactions. ${ }^{2,3}$ This has been achieved by combining various structural characterization techniques, kinetic investigations, and computational studies for each system.

The establishment of a similar molecular view of heterogeneous catalysis has been hampered for a number of reasons. Experimentally, it has proven difficult to bridge the so-called "pressure gap," which refers to the fact that, whereas heterogeneous catalysis usually takes place in reactive gases at pressures between 1 and 200 bars, the structural characterization of surfaces is mostly performed under ultrahigh vacuum conditions. Thus, it is often an open question if the results from such studies are at all comparable. Similarly, the "material gap" refers to the difficulty of comparing results obtained on model single crystal surfaces with those of industrial catalysts, which usually feature nanosized crystals distributed on a high-surface area support. Not only are the morphologies of the catalytic materials different, their interactions with the support can also play a large role ${ }^{4}$ (see Fig. 1).

There are, however, new developments, which show that we are now on the way toward a new, molecular-scale picture of the way solids work as catalysts. By a combination of new theoretical methods, detailed experiments on model systems, and synthesis and in situ characterization of nanostructured catalysts, we are witnessing the first examples of complete atomic-scale insight into the structure and mechanism of surface-catalyzed reactions. This insight has already proven its value by enabling a rational design of new catalysts. 




FIG. 1. (Color) Heterogeneous catalysis at different length scales: from reactor design to molecular level insight.

\section{DISCOVERY OF HETEROGENEOUS CATALYSTS}

The discovery and development of new catalysts is central to improving industrial chemical processes. Even though our understanding of the way solid surfaces can interact with gas phase molecules, break them down, and form new products has increased enormously, ${ }^{5-7}$ catalysts are still predominantly developed by an intuitive trial-and-error approach. Recently, this approach has been revolutionized by the introduction of parallel synthesis and screening methods. ${ }^{8}$ Application of very advanced experimental equipment has increased the rate of preparation, processing, and testing of catalysts from a few catalysts per week to thousands of catalysts per day. ${ }^{9}$ It is clear that widespread use of high throughput synthesis and screening methods will dramatically increase our already vast empirical knowledge about heterogeneous catalysts, facilitating the optimization of existing catalysts as well as the discovery of entirely new systems.

Implementation of new and faster screening methods in heterogeneous catalysis also presents a significant challenge. In particular, the complex and dynamic structure of heterogeneous catalysts poses difficulties for a systematic approach. Additionally, the activity of the catalyst is often strongly dependent on how the ingredients are introduced onto the support material, the detailed method for transforming the catalyst precursor into the active catalyst, and also on the presence of various trace impurities. This means that if a particular composition is found to catalyze a reaction, this "hit" will definitely represent an interesting new catalyst possibility. However, it cannot be concluded that if the composition did not represent a hit it is not a potential catalyst. It could just be that the preparation method used was not adequate for this system.

The development of a detailed molecular level understanding of heterogeneous catalysis offers an alternative to the empirical catalyst screening methods. If the understand- ing is precise enough, it should be possible to design catalysts atom by atom. Such a method would have its own problems, it may, for instance, not be possible to synthesize the best catalyst composition and structure. However, undoubtedly, the parallel synthesis and screening methods would significantly benefit from being supplemented by an insightinspired approach to heterogeneous catalysts.

In the following, we will briefly discuss some of the latest developments toward establishment of a molecular level understanding of heterogeneous catalysts and the first attempts at using it in catalyst design. In order to focus the presentation, we will concentrate on the simplest reactions catalyzed by transition metals.

\section{THE NATURE OF THE ACTIVE SITE}

The active site is a key concept in heterogeneous catalysis. ${ }^{10}$ It is a term used to describe the specific place on the surface of a catalyst where the chemical reactions take place. Identification of the active site must be the first step in the design of better catalysts. Unfortunately, this insight is rarely available because it is hard to catch the reactants on the fly during the reaction. The new most recent advances in our understanding of the active site are driven mainly by two developments. First, a complete in situ atomic-scale picture of the real nanoparticle catalysts has been obtained during reaction. Second, electronic structure calculations have reached a level of accuracy and speed such that they can be used to pinpoint the transition states for molecular reorganizations on the surface. In combination with the detailed experiments on well defined model systems, the electronic and geometrical factors determining the reactivity for the simple surface chemical reactions have finally been elucidated.
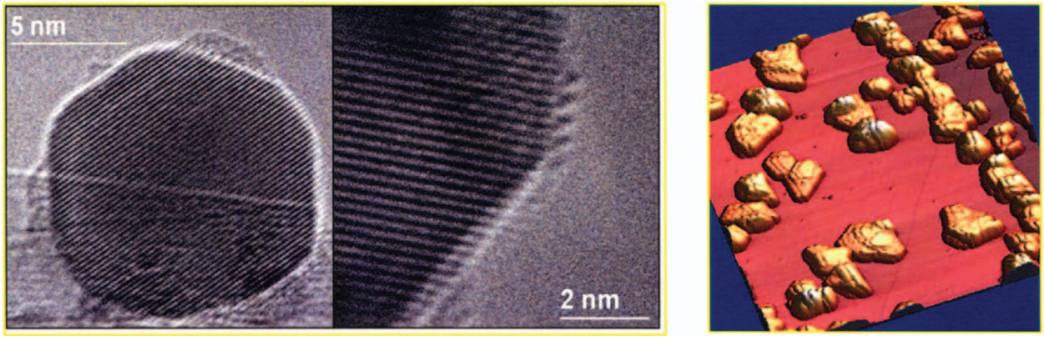

FIG. 2. (Color) Left: in situ images of a supported Ru catalyst recorded at $552{ }^{\circ} \mathrm{C}$ and 5.2 mbars in a gas composition of 3:1 $\mathrm{H}_{2} / \mathrm{N}_{2}$ (from Ref. 15). Right: STM image of Ru nanoparticles supported on graphite. The catalytically active steps can be seen directly (from Ref. 16). 

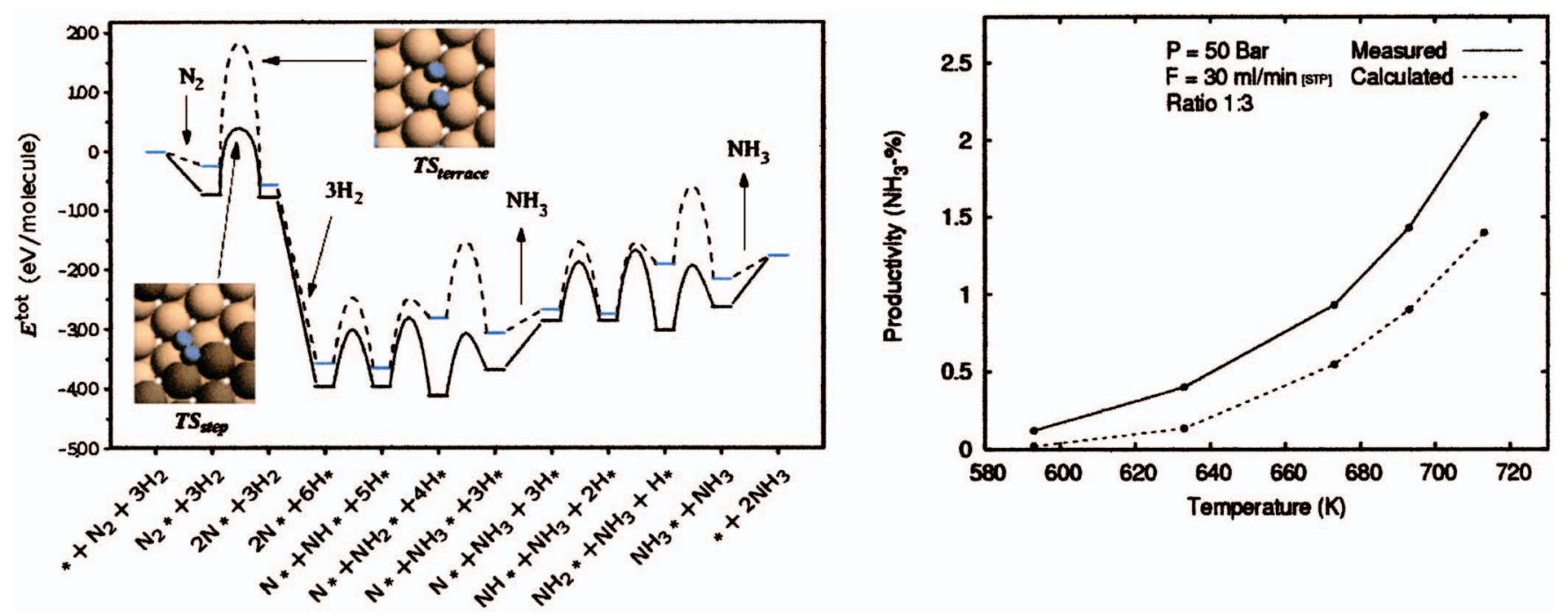

FIG. 3. (Color) Left: Calculated energy diagram for $\mathrm{NH}_{3}$ synthesis over a $\mathrm{Ru}$ surface. Energetics for both the flat surface (dashed lines) and the stepped surface (solid lines) are shown. All energies are shown relative to $\mathrm{N}_{2}$ and $\mathrm{H}_{2}$ in the gas phase. Starting from the left, $\mathrm{N}_{2}$ is first adsorbed on the active site (*), with a weak bond. Then, it dissociates with a sizable activation barrier which depends strongly on the surface structure. $\mathrm{H}_{2}$ adsorbed dissociatively with no activation barrier. When atomic nitrogen $\left(\mathrm{N}^{*}\right)$ and hydrogen $\left(\mathrm{H}^{*}\right)$ atoms are present on the surface, they start combining to form adsorbed $\mathrm{NH} \mathrm{NH}_{2}$, and $\mathrm{NH}_{3}$ which finally desorb from the surface. The geometry of the transition state structures for $\mathrm{N}_{2}$ dissociation on the two surfaces are shown in the insets. Right: ammonia synthesis productivity under industrial conditions calculated directly from the potential energy diagram compared to measurements on a real supported Ru catalyst (from Ref. 18).

\section{The structure of the working catalyst}

Over the last decade, a wide range of so-called in situ or operando $^{11-13}$ characterization techniques has been developed, opening up the possibility of characterizing the structure of heterogeneous catalysts under realistic working conditions. One of the most promising possibilities is the recent development of high-resolution transmission electron microscopy (TEM) of catalysts at elevated temperatures and in the presence of the relevant gas mixtures. ${ }^{14}$ Figure 2 shows images of a ruthenium-based ammonia synthesis catalyst in its working state with atomic-scale resolution of the active metal nanoparticles. ${ }^{15}$ The figure also illustrates the power of scanning tunneling microscopy (STM) in giving a very detailed picture of the structure of Ru particles on a carbon support. ${ }^{16}$

The images of the catalyst during reaction clearly show the existence of planar crystalline close packed surfaces even though the catalyst particles are only a few nanometers in diameter. It is, however, also evident that there is a large number of atomic-height steplike defects particularly around the corners of the catalyst particles. This makes it possible to make structural models of the possible active sites, but the experiments themselves cannot determine which part of the structure is responsible for the catalytic action.

\section{The potential energy diagram}

Quantum chemical calculations have also been developed tremendously over the last decade and are now a tool capable of realistically addressing the stability of intermediates as well as reaction energy barriers for surface reactions. This development is largely based on density functional theory (DFT), ${ }^{17}$ which has reached the accuracy and efficiency needed to treat the complex problems of heterogeneous catalysis.
Theoretically, a chemical reaction is described by the potential energy diagram of the reaction. Figure 3 illustrates this for ammonia synthesis on ruthenium surfaces. ${ }^{18}$ This is a good test reaction since it is quite simple, only two reactants and one product. It is also extremely well-characterized experimentally. ${ }^{19-21}$ The potential energy diagram shows the stability of all the intermediates in the process and the activation barriers separating them. The potential energy diagram therefore contains all the information necessary to calculate the rates of the individual elementary steps in the catalytic reaction and the coverage of all the intermediates.

The first step in ammonia synthesis is the adsorption and dissociation of molecular $\mathrm{N}_{2}$. There is a large activation barrier associated with this process, and the calculations show that it is significantly higher on the flat surface than on a stepped surface. This finding is perfectly corroborated by recent experiments. ${ }^{22}$ The active site for the activation of dinitrogen on a metal surface is thus pinpointed by a combination of DFT calculations and experiments. The calculations identify the most active site on the surface as the one where the two $\mathrm{N}$ atoms in the dissociating molecule are best stabilized by bonding to five of the surface atoms rather than four on the flat surface (see insets in Fig. 3). On both surfaces, one $\mathrm{N}$ atom is bound to three $\mathrm{Ru}$ atoms, whereas the other $\mathrm{N}$ atom is bound to two. The advantage of the particular step site considered here (the so-called $B_{5}$ site) is that none of the $\mathrm{Ru}$ atoms within the active site are bound to more than one $\mathrm{N}$ atom at a time. This gives stronger $\mathrm{Ru}-\mathrm{N}$ bonds, resulting in a more stabilized transition state.

The step from the calculated potential energy diagram to the catalytic turn-over rate of the process is quite complicated. On top of the stability of the intermediates and the activation barriers, it requires calculations of all entropy terms and the inclusion of interactions between adsorbed molecules on the surface. If it is all included properly and the 


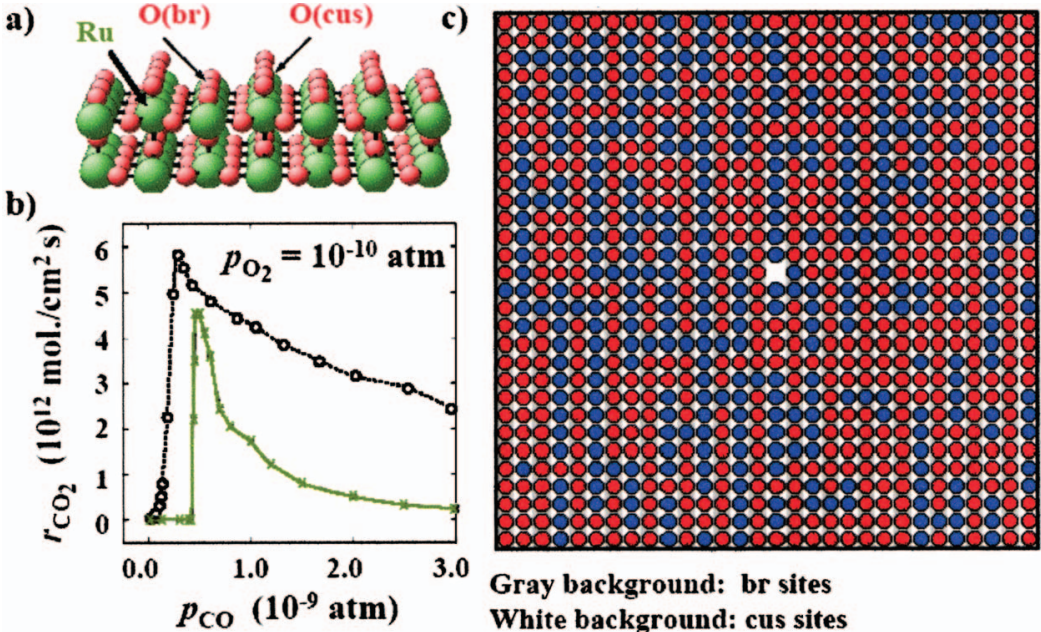

FIG. 4. (Color) (a) Illustration of the catalytically active adsorbed oxygen species $\mathrm{O}^{\text {br }}$ and $\mathrm{O}^{\text {cus }}$ on a $\mathrm{RuO}_{2}(110)$ surface. (b) Rates of $\mathrm{CO}_{2}$ formation as a function of the $\mathrm{CO}$ pressure for a fixed $\mathrm{O}_{2}$ pressure. Experimental values are shown in black (Ref. 26) and the calculated results in green (Ref. 23). (c) A snapshot of the surface during turnover showing adsorbed $\mathrm{O}$ (red) and CO (blue). Reaction takes place at the boundary where $\mathrm{O}$ and $\mathrm{CO}$ meet (from Ref. 23). statistical mechanics of the interacting surface is properly handled using Monte Carlo techniques, it is actually possible to calculate the rate under industrial conditions directly from DFT results. ${ }^{18}$ Using TEM measurements of the size of the catalytic nanoparticles as the only input about the catalyst, the calculations give results in excellent agreement with the experiments, (see Fig. 3). This result provides a very strong validation of the molecular picture of the active sites.

A similarly detailed picture has been developed for another simple catalytic reaction, $\mathrm{CO}$ oxidation over a single crystal $\mathrm{RuO}_{2}(110)$ surface. ${ }^{23}$ Here, again, the statistical dynamics of the surface is included in detail and a large number of possible reaction pathways are included in a kinetic Monte Carlo description of the system. ${ }^{24}$ The resulting rates are in excellent agreement with the detailed surface science experiments on single crystals at low pressures ${ }^{25}$ [see Fig. 4(b)].

These calculations add another important angle to the description of the active site. When $\mathrm{CO}_{2}$ is formed by reaction of adsorbed $\mathrm{O}$ and $\mathrm{CO}$, the pattern of $\mathrm{O}$ and $\mathrm{CO}$ on the surface is crucial since reaction can only take place where the two phases meet. Figure 4(c) illustrates how adsorbed O and $\mathrm{CO}$ are inhomogeneously distributed over the surface, which means that active sites can only be located at the border between these two phases. The active site thus consists of a surface structure and a local arrangement of the adsorbate phases.

In cases where spatial inhomogeneities are not important ${ }^{26}$ mean field kinetic models are sufficient. This has been shown to be the case, for instance, for methanol decomposition on Pt surfaces, where DFT calculations combined with a mean-field kinetic model provide a very good description of experimental data. ${ }^{27}$

\section{TRENDS AND RATIONAL DESIGN}

Having established a molecular level description of a reaction taking place over one surface, the next challenge is to use the model to understand the variations in catalytic activity from one material to the next. This is an important test of the model and it is a crucial step toward catalyst design. The final test of the model is to use the insight to make predictions for hitherto unknown catalysts. In this section, we first consider trends and then turn to the question of catalyst design from insight.

\section{Trends in reactivity}

There are many steps involved in even the simplest surface-catalyzed reactions and this so also for the simplest cases such as ammonia synthesis (Fig. 3). It is therefore critical to identify the parameters which are most important in determining the catalytic activity. The computational techniques then give us unprecedented possibilities for studying trends is activation energies and bond strengths from one metal to the next. For ammonia synthesis, there are two important parameters: the barrier for $\mathrm{N}_{2}$ dissociation and the binding energy of surface-bound nitrogen. The first parameter determines the rate of $\mathrm{N}_{2}$ dissociation, while the latter determines the rate of removal of $\mathrm{N}$ by hydrogenation; the stronger the $\mathrm{N}$ adsorption, the more difficult it is to create new empty sites on the surface where fresh $\mathrm{N}_{2}$ molecules can dissociate. A good catalyst should exhibit a low $\mathrm{N}_{2}$ dissociation barrier as well as a weak $\mathrm{N}$ adsorption bond. Unfortunately, these two parameters cannot be varied independently. Figure 5 indicates that they are linearly dependent in a Brønsted-Evans-Polanyi (BEP)-type relationship. ${ }^{28}$ This means that the barriers for $\mathrm{N}_{2}$ dissociation becomes lower as the $\mathrm{N}$ atoms bind more tightly to the surface; a phenomenon that can be understood by observing that the transition state for $\mathrm{N}_{2}$ dissociation (see Fig. 3) is stretched and resembles the final state, adsorbed $\mathrm{N}$, considerably.

If the linear relationship in Fig. 5 is entered into a kinetic model, the ammonia synthesis rates under industrial conditions can be calculated for a range of metals (see Fig. 5). The dissociative $\mathrm{N}_{2}$ chemisorption energy can be used to characterize the metal since the two parameters of importance for each metal are linearly related. The predictions resulting from combining the DFT calculations with the kinetic model predictions completely concur with experimental observations: the best catalyst is $\mathrm{Ru}$, followed by $\mathrm{Os}$ and $\mathrm{Fe}^{29}$

The result in Fig. 5 exemplifies the famous principle of Sabatier. ${ }^{30}$ The best catalyst is one that binds the intermediates not too strongly and not too weakly. The new feature 

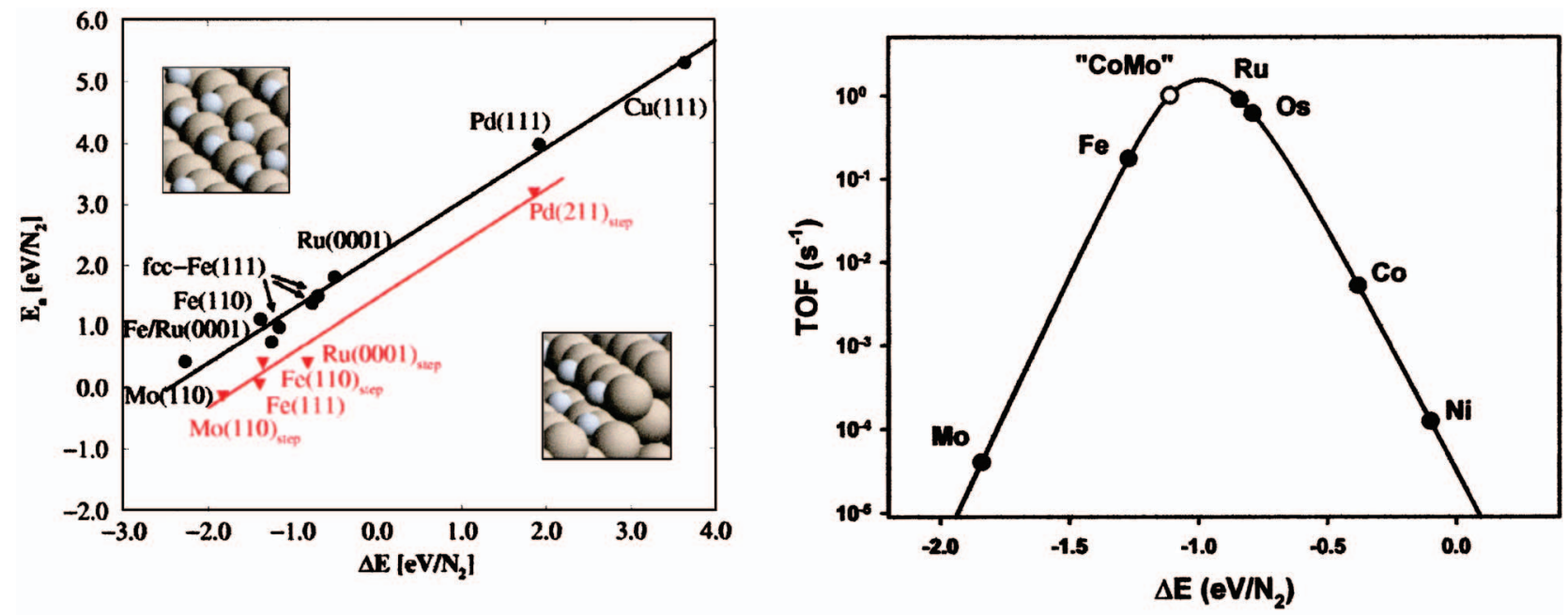

FIG. 5. (Color) Left: calculated activation energies for $\mathrm{N}_{2}$ dissociation plotted as a function of the calculated dissociative $\mathrm{N}_{2}$ chemisorption energy for a number of metals. Right: calculated ammonia synthesis rate per site per second (turn-over frequency, TOF). The values for the individual elemental metals are shown together with the value expected for an alloy consisting of Co and Mo (from Refs. 28 and 31).

introduced by the DFT calculations is that the model is quantitative: The best ammonia catalysts must bind nitrogen with chemisorption energies of the order of $-1 \mathrm{eV}$ $(-100 \mathrm{~kJ} / \mathrm{mol})$. This means that we now have a design criterion.

\section{Rational design}

The volcano plot in Fig. 5 establishes that the nitrogen adsorption energy is a good descriptor for the activity of a metal for ammonia synthesis. We know where the elemental metals are placed on the volcano curve, Fig. 5, but there are still new possibilities if we consider alloys where two or more metals mix in the active site. If the adsorption properties of a mixed active site are somehow an average of those of the constituent atoms, one should be able to identify alloys with the optimum $\mathrm{N}$ chemisorption energy by alloying metals to the left with those to the right of the optimum in Fig. 5. This approach was used to guide the design of a new CoMobased alloy catalyst for ammonia synthesis, as indicated in Fig. 5. ${ }^{31}$ An alloy catalyst with the composition $\mathrm{Co}_{3} \mathrm{Mo}_{3} \mathrm{~N}$ was synthesized and it turned out that under certain experimental conditions it has a catalytic activity higher than that of a state-of-the-art promoted ruthenium catalyst. It was also established that the adsorption properties of a mixed active site with both $\mathrm{Co}$ and Mo are indeed intermediate between those of pure Co and Mo.

The first example of a computational screening for a new catalyst was recently provided for the industrially important methanation reaction. ${ }^{32,33}$ As for ammonia synthesis, the dissociative chemisorption energy of the least reactive reactant,


FIG. 6. (Color) Left: Pareto plot of catalysts predicted to be good compromises with respect to cost and activity for methanation. The positions of the catalysts are determined by the cost of their constituent elements vs their distance from the optimal dissociative chemisorption energy for CO with respect to the experimentally observed optimum (see inset). Right: measured rate of methanation for different Ni-Fe alloy catalysts (adapted from Ref. 32). 



FIG. 7. (Color) (a) Identification of the active site and transition state configurations for epoxidation (EO) and complete oxidation $\left(\mathrm{CO}_{2}\right)$ of ethylene over $\mathrm{Ag}(111)$. (b) Alloying affects the two transition states differently. (c) Calculated change in the difference in activation barriers for the two competing reactions by alloying $\mathrm{Cu}, \mathrm{Pd}$, and $\mathrm{Au}$ into $\mathrm{Ag}(111) . \mathrm{Cu}$ changes the selectivity toward epoxidation most (from Ref. 34).

$\mathrm{CO}$, could be used as a descriptor for the reaction (see inset in Fig. 6). On the basis of the calculations, it was found that $\mathrm{Fe}-\mathrm{Ni}$ alloys should be superior to the $\mathrm{Ni}$ catalysts used in industry today, both in terms of activity and price. The $\mathrm{Fe}-\mathrm{Ni}$ catalysts also exemplify the interpolation principle: the best elemental metal catalysts are $\mathrm{Co}$ and $\mathrm{Ru}$ (which are quite expensive and therefore not used), and $\mathrm{Ni}$ and $\mathrm{Fe}$ are on the two sides of these metals in terms of the descriptor for the reaction.

When it comes to the rational design of catalysts with increased selectivity, a combined experimental and theoretical study has shown the way. ${ }^{34}$ The epoxidation of ethylene usually takes place over an Ag catalyst. The largest problem in this reaction is that ethylene epoxide is much less stable than the products of complete oxidation, $\mathrm{CO}_{2}$ and $\mathrm{H}_{2} \mathrm{O}$. The best catalyst is therefore one where the rate of epoxidation is much higher than the rate of complete oxidation.

The first step was to use DFT calculations to identify the transition state for the two competing reactions over a
$\operatorname{Ag}(111)$ surface (see Fig. 7). The calculations were then used to study how alloying of other metals into the Ag surface could change the activation energy for the two processes. If the difference between the two barriers is increased relative to $\mathrm{Ag}$, then the alloy should exhibit a larger selectivity toward epoxidation than pure $\mathrm{Ag}$. $\mathrm{Cu}$ was found to increase in this barrier difference, and subsequent synthesis and experimental testing of a $\mathrm{Cu} / \mathrm{Ag}$ alloy catalyst showed that the alloy is, in fact, more selective toward epoxidation than pure Ag. ${ }^{34}$

\section{THE GEOMETRICAL AND ELECTRONIC FACTOR IN CATALYSIS}

A molecular description of heterogeneous catalysis can be made at different levels. Up to now we have mainly focused on the mechanistic level and its description through the potential energy diagrams. One level deeper, the question arises as to which properties of a surface determine the energetics. Why is it that certain surfaces exhibit lower activation barriers than others? Often differences in reactivities from one surface to the next are ascribed to geometrical and electronic effects, and in the following, we will show how these concepts can now be given a quantitative meaning.

We have already discussed some geometrical effects. The differences between flat and stepped Ru surfaces toward the activation of $\mathrm{N}_{2}$ (see Fig. 3) is an example of a geometrical effect determining the catalytic activity of a surface. Figure 5 shows that the geometrical effect applies to $\mathrm{N}_{2}$ activation on other transition metals. For all metals studied the activation energies for dissociation at a step are below those at a close packed surface for a given $\mathrm{N}$ adsorption energy. The same effect has been found for a number of other molecules. ${ }^{35-41}$ Such effects are clearly important in determining the activity of a catalyst. For reactions where steps have a high reactivity, the density of such sites on the supported nanoparticle catalysts is a crucial parameter. The in situ TEM and the STM images of supported Ru particles in Fig. 2 clearly show that such sites are present, and by varying the size of the particle, the step density can be controlled. $^{17}$

The variations in catalytic activity from one metal to the next for a fixed surface geometry (along the BEP lines in Fig. 5 ) and the effects of alloying must originate from variations in the electronic structure of the metal. The electronic structure of a transition metal is quite complicated with itinerant electrons originating from the valence $s$ shell of the metal atoms and more localized $d$ electrons moving in partly occupied bands crossing the Fermi level. The average energy of the $d$ electrons $\epsilon_{d}$ turns out to be particularly important in determining the trends in bond energies from one metal to the next. ${ }^{42-47}$ This is illustrated for the dissociative chemisorption energy of several molecular adsorbates in Fig. 8(b). The higher in energy the $d$ states are relative to the Fermi level, the stronger the bond. This effect is related to the bond formation between the adsorbate valence states and the surface $d$ states. The bond is strongest when the antibonding states that are formed above the $d$ bands are empty. Unlike ordinary bonds in molecules where the filling is determined by the number of electrons in the system, the filling of the 


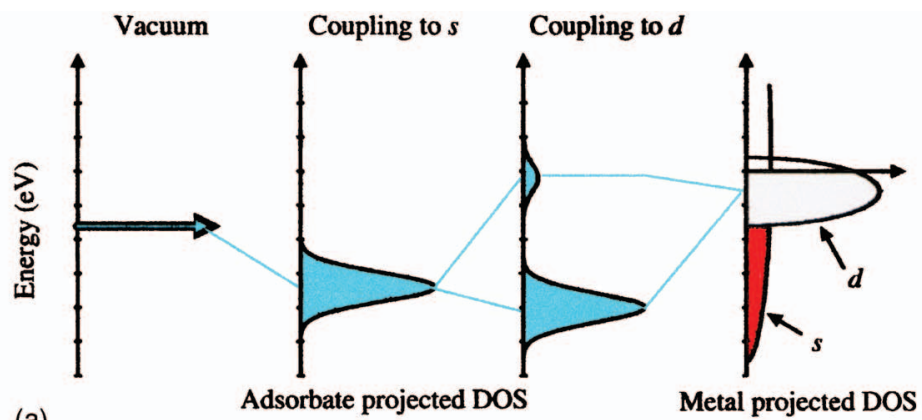

(a)
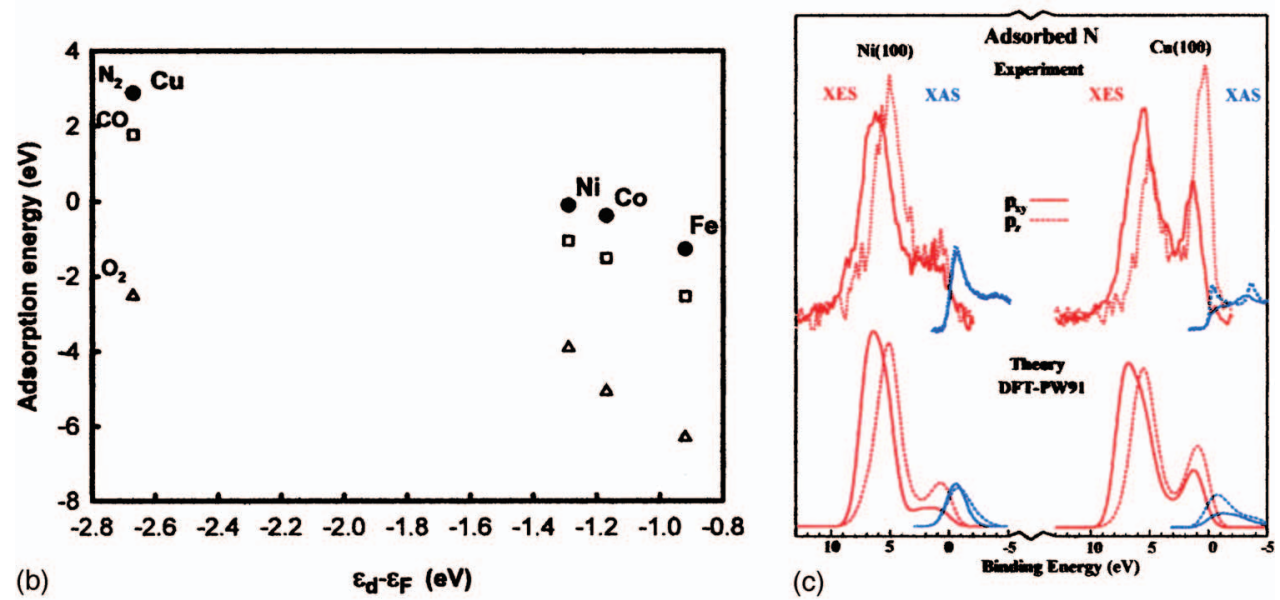

(c)

FIG. 8. (Color) (a) Schematic illustration of the formation of a chemical bond between an adsorbate valence level and the $s$ and $d$ states of a transition metal surface. The coupling to the $s$ states merely leads to a broadening of the adsorbate state, while the coupling to the narrows metal $d$ states results in the formation of bonding and antibonding states. (b) Calculated dissociative dinitrogen, carbon monoxide, and dioxygen chemisorption energies over different $3 d$ transition metals plotted as a function of the center of the transition metal $d$ bands. (c) Top: comparison of the X-ray emission (XES) (occupied states) and x-ray absorption (XAS) (unoccupied states) spectra of atomic $\mathrm{N}$ adsorbed on $\mathrm{Ni}(100)$ and $\mathrm{Cu}(100)$ with separated $p$ components. Bottom: calculated density of states for the same systems. States below the Fermi level are shown in red, while empty states are shown in blue. In order to make the comparison to the experimental results clearer, the spectrum has been broadened by the experimental energy resolution of $\sim 1 \mathrm{eV}$ (from Ref. 42).

antibonding states at a metal surface is determined by their energy relative to the Fermi level, which represents the highest occupied one-electron energy in the system. Shifting the $d$ states up relative to the Fermi level will consequently shift up the antibonding states, leading to a smaller occupation and thus a stronger bond is formed. This picture has been convincingly verified in detailed spectroscopic studies ${ }^{42}$ [see Fig. 8(c)].

Since trends in adsorption energy determine the trends in the catalytic activity for a number of reactions via BEP relations like in Fig. $5,^{40}$ the understanding of trends in bond energies directly provide us with an understanding of trends in activation energies. We therefore have a quite detailed picture of an important electronic factor determining the catalytic activity for some simple reactions on transition metal surfaces.

\section{OUTLOOK}

The emerging molecular level understanding of catalysis is the result of a rapid development in experimental and theoretical methods over that last decade or two. As a result, heterogeneous catalysis is no longer a "black art." The elementary processes can be described in detail and the role of the surface has been quantified. However, we are still just at the beginning. The systems and catalysts that have been de- scribed up to now are all quite simple; the catalysts are usually metals and the reactants and products are simple and few.

There are many challenges ahead. More complex reactions and not least more complex catalysts need to be understood. Again, new experimental methods and approaches offer new hope. It has recently become possible to study nanoscale metal particles on a support directly by a combination of STM and other methods, $4,16,48,49$ and together with the in situ experimental techniques for the characterization of real catalysts, ${ }^{11-15}$ the new theoretical possibilities, ${ }^{50,51}$ new spectroscopic techniques, ${ }^{42}$ and new synthesis routes from nanotechnology, ${ }^{52,53}$ catalysis science and development is at the beginning of a new era.

The requirements to catalytic processes in terms of energy efficiency and selectivity are extremely demanding and there is a strong need for concepts and descriptors that can facilitate catalyst development. Every day in the laboratory decisions are made on the basis of concepts or intuition. Access to better descriptors could also streamline high throughput screening methods as the field of possible catalysts can be narrowed down by screening for the descriptors rather than making complete measurements of catalytic rates. In the end, the progress in the computational methods will most probably mean that the primary screening will be in silico. 


\section{ACKNOWLEDGMENTS}

The Center for Sustainable and Green Chemistry is sponsored by the Danisk National Research Foundation and the Center for Atomic-scale Materials Design is sponsored by the Lundbeck Foundation. We thank Bjerne Clausen, Haldor Topsøe A/S for providing Fig. 1.

${ }^{1}$ I. Maxwell, Stud. Surf. Sci. Catal. 101, 1 (1996).

${ }^{2}$ Applied Homogeneous Catalysis with Organometallic Compounds, 2nd ed., edited by W. A. Herrmann and B. Cornils (Wiley, New York, 2002); K. N. Ferreira, T. M. Iverson, K. Maghlaoui, J. Barder, and S. Iwata, Science 303, 1831 (2004).

${ }^{3}$ Gao J. Garcia-Viloca, M. Karplus, and D. G. Truhlar, Science 303, 186 (2004); P. E. M. Siegbahn, J. W. Tye, and M. B. Hall, Chem. Rev. 107, 4414 (2007)

${ }^{4}$ M. Valden, X. Lai, and D. W. Goodman, Science 281, 1647 (1998); H. J. Freund, Surf. Sci. 500, 271 (2002).

${ }^{5}$ J. M. Thomas and W.-J. Thomas, Principle and Practice of Heterogeneous Catalysis (VCH, Weinheim, 1997).

${ }^{6}$ I. Chorkendorff and H. Niemantsverdriet, Concepts of Modern Catalysis and Kinetics (Wiley-VCH, Weinheim, 2003).

${ }^{7}$ Chemical Bonding at Surfaces and Interfaces, edited by A. Nilsson, L. G. M. Pettersson, and J. K. Nørskov (Elsevier, Amsterdam, 2008).

${ }^{8}$ P. J. Cong, R. D. Doolen, Q. Fan, D. M. Giaquinta, S. H. Guan, E. W. McFarland, D. M. Poojary, K. Self, H. W. Turner, and W. H. Weinberg, Angew. Chem., Int. Ed. 38, 484 (1999); C. Hoffmann, A. Wolf, and F. Schuth, ibid. 38, 2800 (1999).

${ }^{9}$ S. Senkan, Angew. Chem., Int. Ed. 40, 312 (2001).

${ }^{10}$ H. S. Taylor, Trans. Faraday Soc. 28, 131 (1932); B. Lang, R. W. Joyner, and G. A. Somorjai, Surf. Sci. 30, 454 (1972).

${ }^{11}$ H. Topsøe, J. Catal. 216, 155 (2002).

${ }^{12}$ J. D. Grunwaldt and B. S. Clausen, Top. Catal. 18, 37 (2002).

${ }^{13}$ J. M. Thomas, Angew. Chem., Int. Ed. 38, 3588 (1999).

${ }^{14}$ P. L. Gai and E. D. Boyes, Electron Microscopy of Heterogeneous Catalysts (Institute of Physics, London, 2002).

${ }^{15}$ T. W. Hansen, J. B. Wagner, P. L. Hansen, S. Dahl, H. Topsøe, and C. J. H. Jacobsen, Science 294, 1508 (2001).

${ }^{16}$ J. Hrbek and J. Rodriguez, J. Am. Chem. Soc. 126, 8576 (2005).

${ }^{17}$ W. Kohn, Rev. Mod. Phys. 71, 1253 (1999).

${ }^{18}$ K. Honkala, A. Hellman, I. N. Remediakis, A. Logadottir, A. Carlsson, S. Dahl, C. H. Christensen, and J. K. Nørskov, Science 307, 555 (2005).

${ }^{19}$ R. Schlögl, Angew. Chem., Int. Ed. 42, 2004 (2003).

${ }^{20}$ G. J. Ertl, J. Vac. Sci. Technol. A 1, 1247 (1983).

${ }^{21}$ N. Materer and G. A. Somorjai, Top. Catal. 1, 215 (1994).

${ }^{22}$ S. Dahl, A. Logadottir, R. C. Egeberg, J. H. Larsen, I. Chorkendorff, E. Törnqvist, and J. K. Nørskov, Phys. Rev. Lett. 83, 1814 (1999).

${ }^{23}$ K. Reuter, D. Frenkel, and M. Scheffler, Phys. Rev. Lett. 93, 116105 (2004).

${ }^{24}$ S. Ovesson, A. Bogicevic, and B. I. Lundqvist, Phys. Rev. Lett. 83, 2608 (1999); E. W. Hansen and M. Neurock, J. Catal. 196, 241 (2000).

${ }^{25}$ J. Wang, C. Y. Fan, K. Jacobi, and G. Ertl, J. Phys. Chem. B 106, 3422 (2002); C. H. F. Peden and D. W. Goodman, J. Chem. Phys. 90, 1360 (1986).

${ }^{26}$ B. Temel, H. Meskine, K. Reuter, M. Scheffler, and H. Metiu, J. Chem.
Phys. 126, 204711 (2007)

${ }^{27}$ S. Kandoi, J. Greeley, M. A. Sanchez-Castillo, S. T. Evans, A. A. Gokhale, J. A. Dumesic, and M. Mavrikakis, Top. Catal. 37, 17 (2006).

${ }^{28}$ A. Logadottir, T. H. Rod, J. K. Nørskov, B. Hammer, S. Dahl, and C. J. H. Jacobsen, J. Catal. 197, 229 (2001).

${ }^{29}$ Ammonia: Catalysis and Manufacture, edited by K. Aika and K. Tamaru (Springer, Heidelberg, 1995).

${ }^{30} \mathrm{P}$. Sabatier, La Catalyse en Chimie Organique (Beranger, Paris, 1920).

${ }^{31}$ C. J. Jacobsen, S. Dahl, B. S. Clausen, S. Bahn, A. Logadottir, and J. K. Nørskov, J. Am. Chem. Soc. 123, 8404 (2001).

${ }^{32}$ M. P. Andersson, T. Bligaard, A. Kustov, K. E. Larsen, J. Greeley, T. Johannessen, C. H. Christensen, and J. K. Nørskov, J. Catal. 239, 501 (2006).

${ }^{33}$ J. Sehested, K. E. Larsen, A. L. Kustov, A. M. Frey, T. Johannessen, T. Bligaard, M. P. Andersson, J. K. Nørskov, and C. H. Christensen, Top. Catal. 45, 9 (2007)

${ }^{34}$ S. Linic, J. Jankowiak, and M. A. Barteau, J. Catal. 224, 489 (2004).

${ }^{35}$ T. Zambelli, J. Wintterlinn, J. Trost, and G. Ertl, Science 273, 1688 (1996).

${ }^{36}$ B. Hammer, Phys. Rev. Lett. 83, 3681 (1999); Z. P. Liu and P. Hu, J. Am. Chem. Soc. 125, 1958 (2003).

${ }^{37}$ T. Zubkov, G. A. Morgan, Jr., J. T. Yates, Jr., O. Kuhlert, M. Lisowski, R. Schillinger, D. Fick, and H. J. Jansch, Surf. Sci. 526, 57 (2003).

${ }^{38}$ P. Gambardella, Z. Sljivancanin, B. Hammer, M. Blanc, K. Kuhnke, and K. Kern, Phys. Rev. Lett. 87, 056103 (2001).

${ }^{39}$ I. M. Ciobica and R. A. van Santen, J. Phys. Chem. B 106, 6200 (2002).

${ }^{40}$ J. K. Nørskov, T. Bligaard, A. Logadottir, S. Bahn, L. B. Hansen, M. Bollinger, H. Bengaard, B. Hammer, Z. Sljivancanin, M. Mavrikakis, Y. Xu, S. Dahl, and C. J. H. Jacobsen, J. Catal. 209, 275 (2002).

${ }^{41}$ M. Mavrikakis, M. Bäumer, H. J. Freund, and J. K. Nørskov, Catal. Lett. 81, 153 (2002); R. T. Vang, K. Honkala, S. Dahl, E. K. Vestergaard, J. Schnadt, E. Lægsgaard, B. S. Clausen, J. K. Nørskov, and F. Besenbacher, Nat. Mater. 4, 160 (2005).

${ }^{42}$ A. Nilsson, L. G. M. Pettersson, B. Hammer, T. Bligaard, C. H. Christensen, and J. K. Nørskov, Catal. Lett. 100, 111 (2005).

${ }^{43}$ M. Mavrikakis, B. Hammer, and J. K. Nørskov, Phys. Rev. Lett. 81, 2819 (1998)

${ }^{44}$ M. Gajdos, A. Eichler, and J. Hafner, J. Phys.: Condens. Matter 16, 1141 (2004)

${ }^{45}$ O. M. Loevvik and R. A. Olsen, J. Chem. Phys. 118, 3268 (2003).

${ }^{46}$ A. Roudgar and A. Gross, Phys. Rev. B 67, 33409 (2003).

${ }^{47}$ V. Pallassana and M. Neurock, J. Catal. 191, 301 (2000).

${ }^{48}$ K. H. Hansen, T. Worren, S. Stempel, E. Lægsgaard, M. Baumer, H. J. Freund, F. Besebbacher, and I. Steensgaard, Phys. Rev. Lett. 83, 4120 (1999).

${ }^{49}$ C. T. Campbell, S. C. Parker, and D. E. Starr, Science 298, 811 (2002).

${ }^{50}$ F. Abild-Pedersen, J. Greeley, F. Studt, J. Rossmeisl, T. R. Munter, P. G. Moses, E. Skulason, T. Bligaard, and J. K. Nørskov, Phys. Rev. Lett. 99, 016105 (2007).

${ }^{51}$ P. Raybaud, J. Hafner, G. Kresse, S. Kasztelan, and H. Toulhoat, J. Catal. 190, 128 (2000); A. Michaelides, Z.-P. Liu, C. J. Zhang, A. Alavi, D. A. King, and P. Hu, J. Am. Chem. Soc. 125, 3704 (2003).

${ }^{52}$ B. Kasemo, S. Johansson, H. Persson, P. Thormahlen, and V. P. Zhdanov, Top. Catal. 13, 43 (2000).

${ }^{53}$ T. Tsirlin, J. Zhu, J. Grunes, and G. A. Somorjai, Top. Catal. 19, 165 (2002). 